JKEP

Vol 6, No 2 (2021)

ISSN: 2338-9095 (Print)

ISSN: 2338-9109 (online)

\title{
Clinical Evidence Based Nursing (EBNP) Penggunaan Berg Balance Scale Untuk Mengkaji Keseimbangan Pada Pasien Stroke
}

\author{
Dwi Kartika Rahayuningtyas ${ }^{1}$, Ratna Sitorus ${ }^{2}$, I Made Kariasa ${ }^{3}$, Yunisar Gultom ${ }^{4}$ \\ ${ }^{1}$ Poltekkes Kemenkes Jakarta III \\ ${ }^{2,3}$ Universitas Indonesia \\ ${ }^{4}$ Rumah Sakit Umum Pusat Nasional dr Cipto Mangunkusumo \\ Email :tyaas2614@gmail.com
}

Artikel history
Dikirim, Des 15th, 2020
Ditinjau, Nop 18th, 2021
Diterima, Nop 20th, 2021

\begin{abstract}
Stroke can affect balance. Balance is the ability to maintain the body in a balanced position both in static and dynamic conditions. However, the assessment of the existing balance is only done in a static state in stroke patients. The balance assessment describes the balance of stroke patients so that they can be written on asessment form and the transfer record and can determine the need for balance training as one of the rehabilitation of stroke patients. This EBN application aims to find out the use of Berg Balance Scale to assess the balance of both static and dynamic conditions in stroke patients. The method used is conducting PICO analysis, searching database, critical appraisal, and determining relevant journals. EBN implementation was carried out on 10 people who had a stroke in zone A on the 5th floor of Building A RSUPN Dr. Cipto Mangunkusumo. This study uses the Berg Balance Scale scale in Indonesian. The analysis showed that stroke patients who experienced balance disorders were 7 people and did not experience a balance of 3 people $B B S$ can assess the balance of stroke patients in accordance with existing evidence. BBS can be used as a balance assessment in stroke patients.
\end{abstract}

Keywords: balance disorder, berg balance scale, stroke.

\begin{abstract}
ABSTRAK
Stroke bisa mempengaruhi keseimbangan. Keseimbangan merupakan kemampuan tubuh dalam mempertahankan tubuh dalam posisi seimbang baik dalam keadaan statis maupun dinamis. Namun, pengkajian keseimbangan yang ada baru dilakukan dalam keadaan statis pada pasien stroke. Pengkajian keseimbangan menggambarkan keseimbangan pasien stroke sehingga bisa dituliskan pada format pengkajian keperawatan dan catatan transfer serta dapat menentukan kebutuhan latihan keseimbangan sebagai salah satu rehabilitasi pasien stroke. Penerapan EBN ini bertujuan mengetahui penggunaan Berg Balance Scale untuk mengkaji keseimbangan baik dalam keadan statis maupun dinamis pada pasien stroke. Metode yang digunakan adalah melakukan analisa PICO, searching database, critical appraisal, dan menentukan jurnal yang relevan. Penerapan EBN dilakukan pada 10 orang yang mengalami stroke di zona A lantai 5 Gedung A RSUPN dr Cipto Mangunkusumo. Studi ini menggunakan skala Berg Balance Scale dalam bahasa Indonesia.
\end{abstract}


Analisis menunjukkan bahwa pasien stroke yang mengalami gangguan keseimbangan sebanyak 7 orang dan tidak mengalami keseimbangan sebanyak 3 orang. BBS bisa menilai keseimbangan pasien stroke sesuai dengan evidence yang ada. BBS bisa digunakan sebagai pengkajian keseimbangan pada pasien stroke.

Kata kunci : stroke, Berg Balance Scale, gangguan keseimbangan

\section{PENDAHULUAN}

Stroke merupakan urutan kedua penyakit mematikan setelah penyakit jantung Angka kejadian stroke di dunia kira-kira 200 per 100.000 penduduk dalam setahun. Di Indonesia diperkirakan setiap tahun terjadi 500.000 penduduk terkena serangan stroke dan sekitar $25 \%$ atau 125.000 orang meninggal sedangkan sisanya mengalami cacat ringan bahkan bisa menjadi cacat berat (Pudiastuti, 2011). Stroke menjadi penyebab kematian nomor tiga dan merupakan penyebab cacat permanen terbesar di Indonesia (Riskesdas, 2018).

Prevalensi penyakit stroke juga meningkat seiring bertambahnya umur. Kasus stroke tertinggi adalah umur 75 tahun keatas $(43,1 \%)$ dan lebih banyak pria $(7,1 \%)$ dibandingkan dengan wanita (6,8\%) (Depkes, 2013).

Riskesdas 2018 menunjukkan prevalensi Penyakit Tidak Menular mengalami kenaikan jika dibandingkan dengan Riskesdas 2013, antara lain stroke. Prevalensi stroke naik dari 7\% menjadi 10,9\% (Riskesdas, 2018). Sekitar $30 \%$ dari penderita stroke meninggal dalam jangka waktu tiga bulan. Namun, lebih dari $50 \%$ pasien yang selamat bisa memulihkan kemampuan perawatan diri mereka dan kurang dari $20 \%$ pasien yang menderita cacat berat.

Stroke dalam istilah medis disebut "penyakit pembuluh darah otak". Penyebabnya terjadi karena kurangnya pasokan darah ke otak atau terhambat karena hal-hal tertentu, sehungga terjadi pengurangan kadar oksigen dalam selsel otak yang terjadi secara mendadak. Sel-sel otak dapat mengalami kerusakan dan kehilangan fungsinya dalam waktu beberapa menit. Akibatnya, terjadinya kerusakan pada otak dapat memengaruhi fungsi tubuh yang dikendalikan oleh bagian sel-sel otak yang rusak tersebut.

Gangguan sensorik motorik dapat menyebabkan gangguan keseimbangan termasuk kelemahan otot, penurunan fleksibilitas jaringan lunak, serta gangguan kontrol motorik dan sensorik sehingga terjadi penurunan aktifitas pada pasien stroke. Kontrol motorik yang berkurang mengakibatkan hilangnya koordinasi, hilangnya kemampuan mempertahankan keseimbangan tubuh dan mengontrol pergerakan dari batang tubuh (trunk) serta postur sehingga berdampak pada aktifitas mobilitas fungsional seperti berjalan, keseimbangan, menggenggam, berpindah 
posisi (transfer) (Haruyama, Kawakami, Otsuka, 2017). Keseimbangan adalah salah satu komponen kunci yang menentukan kemampuan pasien setelah stroke dan perkusor esensial terhadap salah satunya restorasi kemandirian aktivitas sehari-hari (Loewen\&Anderson, 1990 dalam Bambirra, Rodgues, Faria, Paula, 2015) . Pada penelitian prospektif yang dilakukan oleh Tsang\&Mark (2004) kinerja keseimbangan dapat memprediksi mobilitas pasien stroke saat pulang.

Kinerja keseimbangan perlu dilakukan pengkajian. Berdasarkan hasil penelusuran evidence based practice, sejumlah bukti menyarankan bahwa Berg Balance Scale (BBS) adalah pengukur yang valid untuk keseimbangan individu dengan Cerebro Vasculer Accident/CVA (Stevenson, 2001). BBS telah teridentifikasi sebagai alat pengkajian keseimbangan yang paling umum dilakukan pada pasien stroke (Blum dan Bitensky, 2008 dalam Makizako, et al, 2015). BBS bisa digunakan dalam 2 situasi. Situasi pertama yaitu BBS digunakan saat masuk, sebelum, dan beberapa intervensi yang dilakukan dan perubahan skor dipertimbangkan ketika klinisi menentukan apakah intervensi tersebut sesuai atau tidak untuk pasien tersebut (Stevenson, 2001 dan Tyson\&DeSouza, 2004 dalam Bambirra,
Rodgues, Faria, Paula, 2015). Situasi kedua yaitu BBS digunakan untuk menggambarkan keseimbangan individual pada catatan transfer ketika individu pindah dari 1 ruang perawatan ke ruang perawatan berikutnya (Stevenson, 2001).

BBS merupakan alat pengkajian keseimbangan yang sensitif. Hal ini dibuktikan dalam penelitian yang dilakukan oleh Wood-Dauphinee et al (1997) dalam Stevension (2001) yang mengkaji kinerja BBS, Fugl-Meyer Scale (FMS), dan Barthel Index (BI) pada individu dengan CVA pada 2,6, dan 12 minggu post onset kejadian neurologi. BBS ditemukan memiliki efisiensi relatif lebih besar dibandingkan FMS (1.0 versus 0.65) tetapi lebih buruk dibandingkan BI (1.24 versus 1.0) untuk periode waktu antara 2 dan 12 minggu post CVA. BBS memiliki efisiensi lebih besar daripada FMS dan BI ( 1.0 versus 0.30 versus 0.68 ) untuk periode waktu antara 6 sampai 12 minggu post CVA. BBS lebih disarankan dibandingkan Functional Reach untuk digunakan pada pasien stroke karena memberikan wawasan tambahan tentang kemungkinan etiologi atau gangguan keseimbangan (Smith, Hambree, dan Thompson, 2004).

BBS bisa dilakukan oleh multidisiplin penyedia pelayanan kesehatan termasuk perawat (Berg et al, 1989). Berg dan teman- 
teman mendemonstrasikan bahwa BBS memiliki reliabilitas dan validitas yang baik diantaranya pasien stroke (Berg et al, 1992; Wood-Dauphinee\&Williams, 1995; Berg, Word-Daupnhinee, 1992; WoodDauphinee\&Williams, 1997 dalam Park\&Lee, 2016). BBS dikenal sebagai alat yang costeffectiveness, hemat waktu dalam beberapa aspek yaitu mudah dilakukan pada beberapa lokasi, memerlukan perlatan sederhana, bisa dipelajari dengan pelatihan minimal (Park\&Lee, 2016).

Berdasarkan fenomena yang ditemukan penulis di ruang perawatan dan poliklinik neurologi RSUPN dr. Cipto Mangunkusumo, pengkajian keseimbangan dengan BBS belum dilakukan oleh perawat di ruang kelas 3 karena belum tersosialisasi dan belum adanya standar operasional prosedur. Berdasarkan wawancara dengan perawat di ruang kelas 3 lantai 5 zona $\mathrm{A}$, selama ini perawat menggunakan tes romberg untuk menilai kemampuan keseimbangan pasien. Tes romberg diketahui berguna untuk melihat keseimbangan statis, sementara keseimbangan ada keseimbangan statis dan dinamis. BBS mampu mendeteksi keseimbangan statis dan dinamis (Zwitck et al, 2000 dalam Blum\&Bitensky, 2008; Bambirra, Rodgues, Faria, Paula, 2015; dan Park\&Lee, 2016). Di RSUPN dr. Cipto Mangunkusumo, penilaian keseimbangan dengan BBS baru dilakukan oleh fisioterapis untuk semua pasien dengan gangguan keseimbangan pada saat masuk ke ruang neurorestorasi di poliklinik saraf.

Penulis menilai perlunya pengkajian keseimbangan dengan skala BBS. Melalui laporan program EBN ini, penulis ingin mengetahui apakah skala BBS bisa mengkaji keseimbangan pada pasien stroke di RSUP Dr. Cipto Mangunkusomo.

\section{METODE}

Penerapan EBN ini dimulai dengan mengidentifikasi fenomena, analisis menggunakan konsep PICO (problem, intervention, comparison, outcome), searching database, critical appraisal, dan menentukan jurnal yang relevan. Jurnal yang berjudul "Berg Balance Scale and Functional Reach : determining the best clinical tool for acute stroke (Smith, Hembree, Thompson, 2004) menjadi jurnal relevan karena berkaitan dengan manfaat utama BBS yaitu mengkaji pasien stroke di rumah sakit. yang ditulis oleh. Populasi pada penerapan EBN ini adalah seluruh pasien stroke yang menjalani perawatan di ruang rawat inap Neurologi lantai 5 zona A Gedung A RSUPN Dr Cipto Mangunkusumo.

Kriteria inklusi yaitu berumur 18-80 tahun, diagnosis klinis serangan stroke (baik iskemik 
atau hemoragik), memiliki kelemahan salah 1 tubuh, mampu mengikuti perintah, bersedia ikut serta dalam pelaksanaan EBN, tidak ada penggantian sendi, disfungsi vestibular, tambahan penyakit neurologi lain, gangguan lapang pandang, nyeri yang bisa membatasi kemampuan berdiri. Besar sampel 10 pasien stroke.

Pengkajian keseimbangan dilakukan menggunakan Berg Balance Scale (BBS). BBS terdiri dari 14 tugas pergerakan yaitu berdiri duduk lalu berdiri, berdiri tanpa bantuan selama 2 menit, berdiri dengan mata tertutup, berdiri dengan kedua kaki dirapatkan, berdiri lalu duduk, duduk tanpa bantuan di belakangnya, pindah dengan dan tanpa bantuan, mencapai sesuatu dengan lengan yang terjangkau, mengambil benda dari lantai, berputar untuk melihat ke belakang, berputar $360^{\circ}$, menempatkan 1 kaki di kursi secara bergantian, menempatkan 1 kaki di depan, berdiri dengan salah satu kaki. Pengkajian keseimbangan memerlukan ratarata 15 menit (Berg, Wood-Dauphinee, et al, 1992 dalam Park\&Lee, 2016).

Setiap tugas terdiri dari 5 poin skala ordinal dari 0 sampai 4 dengan skor 0 mewakili ketidakmampuan untuk melakukan tugas sampai skor 4 mewakili kemandirian melengkapi tugas. Setiap tugas akan dijumlahkan skornya yang akan bervariasi dari 0-56 dengan skor lebih tinggi mengindikasikan keseimbangan lebih baik dan kinerja kemandirian yang lebih baik (Blum\&Korner-Bitensky, 2008 dalam Park\&Lee, 2016). Skoring BBS dibagi menjadi dua yaitu tidak terjadi gangguan keseimbangan (skor 46-56), dan gangguan keseimbangan (skor 0-45).

Pengkajian keseimbangan dilakukan di lantai 5 zona A RSUP Dr. Cipto Mangunkusomo selama 3 minggu (8-26 April 2019). Rumah sakit ini merupakan rumah sakit tipe A, menjadi tempat rujukan pasien seluruh Indonesia dan merupakan salah satu tempat praktik residensi keperawatan area neurologi.

\section{HASIL}

Gambaran karakteristik pasien yang diikutsertakan dalam pengkajian keseimbangan pada pasien stroke dijelaskan dalam beberapa tabel 1 dan tabel 2 sebagai berikut 
Tabel 1 Gambaran Karakteristik Pasien Stroke Berdasarkan Umur ( $\mathrm{n}=10)$

\begin{tabular}{|c|c|c|c|}
\hline Variabel & Mean & Standar Deviasi & Minimal-Maksimal \\
\hline Umur (tahun) & 45.8 & 10,79 & $26-62$ \\
\hline
\end{tabular}

Tabel 2 Gambaran Karakteristik Pasien Stroke Berdasarkan Jenis Kelamin, Diagnosis Penyakit, dan Onset Stroke $(\mathrm{n}=10)$

\begin{tabular}{|c|c|c|}
\hline Variabel & Frekuensi & Presentase (\%) \\
\hline \multicolumn{3}{|l|}{ Jenis Kelamin } \\
\hline 1. Laki-laki & 3 & 30 \\
\hline 2. Perempuan & 7 & 70 \\
\hline \multicolumn{3}{|l|}{ Diagnosa Medis } \\
\hline 1. Stroke iskemik & 8 & 80 \\
\hline $\begin{array}{l}\text { 2. Stroke } \\
\text { hemoragik }\end{array}$ & 2 & 20 \\
\hline \multicolumn{3}{|l|}{ Onset Stroke } \\
\hline 1. $<7$ hari & 10 & 100 \\
\hline 2. $\geq 7$ hari & 0 & 0 \\
\hline
\end{tabular}

Lama rawat inap pasien stroke biasanya 7 hari jika hemodinamik pasien stabil. Pelaksanaan BBS dilakukan pada pasien rawat inap setelah kondisi hemodinamik stabil dan sebelum pasien pulang ke rumah yaitu pada hari ke-5 dan ke-6, bervariasi dari masing-masing pasien karena tergantung kestabilan hemodinamik pasien. Hemodinamik ini dilihat dari tingkat kesadaran dan tanda-tanda vital. Tingkat kesadaran semua pasien kompos mentis (GCS 15). Tanda - tanda vital masing-masing pasien sebelum dilakukan pengkajian dengan BBS yaitu :

Tabel 3. Hasil Tanda-Tanda Vital

\begin{tabular}{|c|c|c|c|c|c|c|}
\hline No & Pasien & $\begin{array}{c}\text { Tekanan } \\
\text { Darah } \\
(\mathrm{mmHg})\end{array}$ & $\begin{array}{c}\text { Nadi } \\
(\mathbf{x} / \\
\text { menit })\end{array}$ & $\begin{array}{c}\text { Pernapa } \\
\text { san } \\
\text { (x/menit) }\end{array}$ & $\begin{array}{l}\text { Suhu } \\
\left({ }^{0} \mathrm{C}\right)\end{array}$ & $\begin{array}{r}\text { Saturasi } \\
\mathrm{O}_{2}(\%)\end{array}$ \\
\hline 1. & Ny. F & $113 / 80$ & 86 & 18 & 36,2 & 98 \\
\hline 2. & Tn. H & $120 / 70$ & 90 & 17 & 36,5 & 99 \\
\hline 3. & Ny. IP & $121 / 82$ & 87 & 18 & 36,3 & 97 \\
\hline 4. & Ny. RL & $118 / 83$ & 98 & 18 & 36,1 & 97 \\
\hline 5. & Ny.KG & $110 / 70$ & 84 & 17 & 36,6 & 98 \\
\hline 6. & Ny. S & $127 / 85$ & 99 & 18 & 36,7 & 99 \\
\hline 7. & Ny. SR & $114 / 90$ & 78 & 17 & 36,8 & 97 \\
\hline 8. & Ny. Y & $130 / 90$ & 97 & 17 & 36,0 & 98 \\
\hline 9. & Tn. A & $120 / 80$ & 85 & 18 & 36,9 & 99 \\
\hline 10. & Tn. E.F & $117 / 87$ & 88 & 17 & 37 & 97 \\
\hline
\end{tabular}


Tabel 3 Hasil Pengkajian Keseimbangan menggunakan BBS ( $n=10)$

\begin{tabular}{|c|c|c|c|c|c|}
\hline No & Inisial Pasien & $\begin{array}{l}\text { Skor } \\
\text { BBS }\end{array}$ & Interpretasi BBS & Frekuensi & $\begin{array}{l}\text { Persentase } \\
(\%)\end{array}$ \\
\hline 1. & Ny. F & 26 & $\begin{array}{l}\text { Ada gangguan } \\
\text { keseimbangan }\end{array}$ & \multirow{7}{*}{7} & \multirow{7}{*}{70} \\
\hline 2. & Tn. H & 40 & $\begin{array}{l}\text { Ada gangguan } \\
\text { keseimbangan }\end{array}$ & & \\
\hline 3. & Ny. IP & 36 & $\begin{array}{l}\text { Ada gangguan } \\
\text { keseimbangan }\end{array}$ & & \\
\hline 4. & Ny. R.L & 25 & $\begin{array}{l}\text { Ada gangguan } \\
\text { keseimbangan }\end{array}$ & & \\
\hline 5. & Ny. K.G & 15 & $\begin{array}{l}\text { Ada gangguan } \\
\text { keseimbangan }\end{array}$ & & \\
\hline 6. & Ny. S & 36 & $\begin{array}{l}\text { Ada gangguan } \\
\text { keseimbangan }\end{array}$ & & \\
\hline 7. & Ny. S.R & 32 & $\begin{array}{l}\text { Ada gangguan } \\
\text { keseimbangan }\end{array}$ & & \\
\hline 8. & Ny. Y & 46 & $\begin{array}{l}\text { Tidak ada gangguan } \\
\text { keseimbangan }\end{array}$ & \multirow{3}{*}{3} & \multirow{3}{*}{30} \\
\hline 9. & Tn. A & 48 & $\begin{array}{l}\text { Tidak ada gangguan } \\
\text { keseimbangan }\end{array}$ & & \\
\hline 10. & Tn. E.F & 47 & $\begin{array}{l}\text { Tidak ada gangguan } \\
\text { keseimbangan }\end{array}$ & & \\
\hline
\end{tabular}

\section{PEMBAHASAN}

1. Umur

Rerata umur pasien stroke yang dilakukan pengkajian keseimbangan menggunakan BBS adalah 45,8 tahun dengan standar deviasi 10,79 tahun. Umur merupakan salah satu faktor risiko stroke yang tidak dapat diubah. Umur termuda adalah 26 tahun dan umur tertua adalah 62 tahun. Umur pada hasil penerapan EBN hampir sama dengan hasil penelitian yang dilakukan oleh Pajri, Safri, dan Dewi (2017) yang mendapatkan bahwa $40 \%$ pasien stroke berada pada usia 36-50 tahun dan 50\% berada pada usia 51-65 tahun. Menurut American Hearth Association prevalensi kejadian stroke yang diambil dari survei pemeriksaan kesehatan dan nutrisi nasional 2009-2012 didapatkan bahwa usia 20-39 tahun sebanyak 0.9\%; 40-49 tahun sebanyak 4,1\%; 60-79 tahun $11,3 \%$ (Mozaffarian D, et all, 2015). Kejadian penderita stroke biasanya berusia lanjut (60 
tahun ke atas) dan resiko stroke meningkat seiring bertambahnya usia (Nurarif et all, 2013). Hal ini tidak berarti bahwa stroke hanya terjadi pada orang lanjut usia karena stroke dapat menyerang semua kelompok umur (Sustrani, dkk, 2006). Kejadian pada semua kelompok umur ini dilihat dari berbagai kelainan yang menjadi pencetus serangan stroke seperti aneurisma intrakranial, malformasi vaskuler otak, kelainan jantung bawaan (Dian, 2011). Stroke yang menyerang usia lanjut dikarenakan mengalaminya degeneratif organ-organ dalam tubuh (Nurarif et all, 2013) termasuk pembuluh darah otak. Pembuluh darah menjadi tidak elastis terutama di bagian endotel yang mengalami penebalan pada bagian intima, sehingga mengakibatkan lumen pembuluh darah semakin sempit dan berdampak pada penurunan aliran darah (Kristiyawati dkk, 2009). Stroke pada semua golongan usia ini memmungkinkan timbulnya gangguan kontrol motorik termasuk gangguan keseimbangan.

\section{Jenis Kelamin}

Hasil penerapan EBN didapatkan bahwa sebagian besar pasien stroke berjenis kelamin perempuan sebesar $70 \% \quad$ (7 orang). Perempuan memiliki kecendrungan lebih besar terkena stroke setelah usia menopause karena hormon ini berperan dapat melindungi perempuan sampai melewati masa melahirkan anak (Burhanudin, Wahidudin, Jumriani, 2012). Menurut American Hearth Association prevalensi kejadian stroke yang diambil dari survei pemeriksaan kesehatan dan nutrisi nasional 2009-2012 didapatkan bahwa perempuan memiliki persentase lebih tinggi dibandingkan laki-laki pada setiap kelompok usia. Usia 20-39 tahun sebanyak 0,9\% dimana $0,2 \%$ terjadi pada laki-laki dan $0,7 \%$ terjadi pada perempuan; usia 40-49 tahun sebanyak $4,1 \%$ dimana $1,9 \%$ terjadi pada laki-laki dan 2,2\% terjadi pada perempuan ; 60-79 tahun $11,3 \%$ dimana $6,1 \%$ terjadi pada laki-laki dan $5,2 \%$ terjadi pada perempuan (Mozaffarian D, et all, 2015). Persentase yang lebih tinggi pada perempuan ini juga meningkatkan risiko terkena stroke sehingga kerusakan di sel-sel otak juga lebih berisiko. Kerusakan sel-sel otak ini termasuk kerusakan pada gangguan fungsi sensorik dan motorik. Gangguan sensorik dan motorik dapat menyebabkan gangguan keseimbangan termasuk kelemahan otot, penurunan fleksibilitas jaringan lunak sehingga terjadi penurunan aktivitas pada pasien stroke.

\section{Diagnosa Medis}

Sebagian besar diagnosa medis pasien pada penerapan EBN adalah stroke iskemik sebesar $80 \%$ (8 orang). Hal ini sesuai dengan pernyataan Boehme, Esenwa, dan Elkind 
(2017) bahwa sebagian besar (80\%) stroke adalah iskemik walaupun batas relatif stroke hemoragik dan iskemik bervariasi diantara populasi. Penelitian yang dilakukan oleh O’Donnell MJ, et all (2010) menyatakan bahwa sebagian besar $(77,9 \%)$ yaitu sebanyak 2337 responden yang diteliti terdiagnos stroke iskemik. Penyebab stroke iskemik lebih banyak dibandingkan stroke hemoragik dimana penyebab utama stroke hemoragik karena perdarahan intraparenkim atau subarahnoid. Penyebab stroke iskemik dibagi menjadi penyebab subtipe atau kategori yang mewakili penyebab stroke yaitu kardioemboli, aterosklerosis, lakunar, penyebab spesifik lain (diseksi, vaskulitis, kelainan genetik spesifik, dan lainnya) (Adam, et all, 1993 dalam Boehme, Esenwa, dan Elkind, 2017). Pada pasien stroke iskemik penyumbatan yang terjadi menyebabkan fungsi kontol motorik berkurang. Kontrol motorik yang berkurang mengakibatkan hilangnya koordinasi, hilangnya kemampuan mempertahankan keseimbangan tubuh dan mengontrol pergerakan dari batang tubuh (trunk) serta postur sehingga berdampak pada aktifitas mobilitas fungsional seperti berjalan, keseimbangan, menggenggam, berpindah posisi (transfer) (Haruyama, Kawakami, Otsuka, 2017).

\section{Onset Stroke}

Semua pasien yang dikaji keseimbangannya pada penerapan EBN merupakan onset kurang dari 7 hari sebesar $100 \%$ (10 orang). Pada penerapan EBN, pelaksanaannya adalah pasien tidak dapat dikaji minimal 7 hari setelah post stroke seperti yang disarankan jurnal rujukan karena masa perawatan pasien dengan stroke tanpa diagnosa sekunder selama 7 hari perawatan (tergantung kondisi klinis pasien). Pada pasien stroke iskemik fase akut 2-4 hari. Selama fase akut kondisi klinis pasien bisa membaik atau memburuk tergantung penatalaksanaan yang dilakukan. Pada fase akut ini merupakan kondisi kritis pasien dan perlu monitoring ketat kesadarannya dan status neurologisnya penurunan atau tidak. Karena fase akut sangat memungkinkan terjadi perburukan kondisi bila salah melakukan perawatan. Hal ini bisa memungkinkan penambahan edema serebral baik edema sitotoksik maupun edema vasogenik. Apabila fase akut pasien sudah terlewati dan kondisi klinis pasien dalam batas normal tanpa ada perburukan maka pasien akan rehabilitatif sampai hari ke-7 dan diizinkan untuk rawat jalan (Boehme, Esenwa, dan Elkind, 2017). Pada penelitian yang dilakukan oleh Stevenson (2001) mengatakan bahwa semua pasien yang dilakukan pengkajian keseimbangan adalah pasien stroke akut yang stabil secara medis. 


\section{Pengkajian Keseimbangan dengan BBS}

Pada saat pengkajian, ada 3 pasien memiliki skor BBS 3 sampai 4 untuk setiap item sehingga total skor BBS 46-48 yang berarti ketiga pasien ini tidak ada gangguan keseimbangan. Ada 5 pasien yang hanya bisa melakukan kegiatan sesuai item BBS sampai item ke-10 (berputar 360 derajat). Setelah kegiatan ini, pasien cenderung ingin duduk dan tidak mau melakukan kegiatan untuk item ke-11 sampai 14. Pada item ke-11 sampai ke14 diberi skor 0 sehingga total skor masuk dalam kategori ada gangguan keseimbangan. Ada 2 pasien yang mampu melakukan semua tindakan sebanyak 14 item tetapi waktunya lebih lama daripada 8 pasien lainnya yaitu 20 menit. Hal ini karena pasien sangat hati-hati dan khawatir jatuh dalam setiap kegiatan yang diminta saat pengkajian. Total skor BBS pada kedua pasien pun termasuk dalam kategori ada gangguan keseimbangan. Berdasarkan hal di atas, maka disimpulkan bahwa sebanyak 3 pasien tidak ada gangguan keseimbangan dan 7 pasien ada gangguan keseimbangan.

Gangguan keseimbangan pada stroke berhubungan dengan ketidakmampuan untuk mengatur perpindahan berat badan dan kemampuan gerak otot yang menurun sehingga keseimbangan tubuh menurun. Kemampuan tubuh untuk menyeimbangakn di bidang tumpu dapat mengalami gangguan dalam melakukan adaptasi pada gerakan dan kondisi lingkungan. Gangguan keseimbangan terjadi karena hilangnya sensorik dan motorik seperti kelemahan otot, penurunan fleksibilitas jaringan lunak, serta gangguan kontrol motorik maupun sensoris. Otot yang memiliki penurunan fungsi yang terjadi pada ekstremitas bawah dapat menyebabkan penurunan kemampuan dalam menopang atau menyangga dan menyeimbangkan masa tubuh, sehingga mengalami kesulitan untuk memulai mengarahkan, mengukur kecepatan otot dalam mempertahankan keseimbangan tubuh (O'Donnell, et al, 2010).Fungsi yang hilang akibat gangguan kontrol motorik pada pasien stroke mengakibatkan hilangnya koordinasi dan hilangnya kemampuan merasakan keseimbangan tubuh dan kemampuan untuk mempertahankan posisi tertentu. Kesulitan membentuk dan mempertahankan postur yang tepat dapat diketahui saat pasien melakukan gerakan dari duduk ke berdiri maupun dari berdiri ke duduk (Thomson, 2010).

Keterbatasan penerapan yaitu lama rawat pasien stroke di ruang perawatan biasanya 7 hari sehingga waktu pelaksanaan pengkajian keseimbangan dilakukan pada pasien stroke onset hari ke-5 dan 6. Waktu pelaksanaan ini tidak sesuai anjuran dari jurnal rujukan. Namun, berdasarkan jurnal lain (Stevenson, 
2001) pengkajian keseimbangan dengan BBS bisa dilakukan adalah pasien stroke akut yang stabil secara medis.

\section{KESIMPULAN}

Rata-rata umur pasien adalah 45.8 tahun, sebagian besar pasien berjenis kelamin perempuan sebesar $70 \%$ (7 orang), stroke iskemik sebesar $80 \%$ ( 8 orang), dan semua pasien yang dikaji keseimbangannya merupakan onset kurang dari 7 hari sebesar $100 \%$ (10 orang). Hasil pengkajian BBS didapatkan bahwa sebagian besar pasien mengalami gangguan keseimbangan sebanyak 7 orang $(70 \%)$.

Bagi pelayanan keperawatan, paket intervensi keperawatan ini dapat menjadi pertimbangan salah satu intervensi keperawatan mandiri yang dapat dilakukan. Intervensi yang sudah atau akan dilakukan dan gambaran keseimbangan pasien saat transfer antar ruangan dipertimbangkan berdasarkan hasil pengkajian keseimbangan. Bagi pendidikan keperawatan, dapat memberikan pengetahuan serta wawasan yang lebih luas mengenai pengkajian keseimbangan pada pasien stroke serta dapat diintegrasikan dan dikembangkan ke dalam materi terapi mandiri keperawatan.

\section{UCAPAN TERIMA KASIH}

Peneliti mengucapkan terima kasih kepada pihak RSUPN dr. Cipto Mangunkusumo yang telah memberikan kesempatan untuk menerapkan EBN.

\section{REFERENSI}

Alghadir, Al-Eisa, Anwer, dan Sarkar. (2018). Reliability, validity, and responsiveness of thress scales for measuring balance in patients with chronic stroke. Tersedia di http://remote-

lib.ui.ac.id:2235/ehost/pdfviewer/pdfviewe r?vid=0\&sid=1febe11b-2776-4981-a49f592802da68b0\%40sdc-v-sessmgr01

Badan Penelitian dan Pengembangan Kesehatan. (2013). Hasil Utama Riset Kesehatan Dasar 2013. Jakarta : Kementerian Kesehatan RI.

Badan Penelitian dan Pengembangan Kesehatan. (2018). Hasil Utama Riset Kesehatan Dasar 2018. Jakarta : Kementerian Kesehatan RI.

Bambirra Carla, Rodrigues Maria C.d.B, Faria Christina D.C.d.M,\& Paula Fatima R.d. (2015). Clinical Evaluation of Balance in Hemiparetic Adults: A Systematic Review. Doi: $\quad$ http://dx.doi.org.10.1590/01035150.028.001.AR03. ISSN 0103-5150. P.187-200

Berg K, Wood-Dauphinee S, Williams JI, Maki, B: Measuring balance in the elderly: Validation of an instrument. Can. J. Pub. Health, July/August supplement 2:S7-11, 1992.

Berg K, Wood-Dauphinee S, Williams JI, Gayton D: Measuring balance in the elderly: Preliminary development of an instrument. Physiotherapy Canada, 41:304311, 1989. 
Black, J.M., Hawks, J.H. (2009). Keperawatan Medikal Bedah. Manajemen Klinis untuk Hasil yang Diharapkan. Edisi 8 Buku 1. Jakarta : Elsevier.

Bland MD, Sturmoski A, Whitson M, et al. (2012). Prediction of discharge walking ability from initial assessment in a stroke inpatient rehabilitation facility population. Arch Phys Med Rehabilitation;93:14411447.

Blum, Korner-Bitensky. (2008). Usefulness of the Berg Balance Scale in stroke Rehabilitation : a Systematic Review. Physical Theraphy volume 88 , number 5, 559-566

Boehme A.K, Esenwa C, Elkind M.S.V. (2017) Stroke Risk Factors, Genetics, and Prevention. Circulation Research. Doi 10.1161/CIRCRESAHA. $\quad 116.308398$. http: // circres.ahajournal.org.

De Oliveira R, Cacho EW, Borges G. 2006. Post-Stroke Motor and Functional Evaluation: A Clinical Correlation using Fugl-Meyer Assessment Scale, Berg Balance Scale and Barthel Index. Arq Neuropsiquiatr. 64 (3B): 731-5.

Dian, N. (2011). Gambaran faktor resiko terjadinya stroke pada pasien rawat inap di Rumah Sakit Krakatau

Ganvir, Harischandre. (2017). Is Scoring on Berg Balance Scale Affected By Items Being Performed By Sound; d Side or An Affected Side?. Journal of Physiotheraphy \& Physical Rehabilitation. DOI : 10.4172/2573-0312.1000131.

Haruyama, K., Kawakami, M., Otsuka, T. (2017). Effect of Core Stability Training on Trunk Function, Standing Balance, and Mobility in Stroke Patients: A Randomized
Controlled Trial. Neurorehabilitation and Neural Repair 2017, Vol. 31(3)240-249. Diakses dari http://journals.sagepub.com/doi/suppl/10.1 $177 / 1545968316675431$

O'Donnell MJ, Xavier D, Liu L, et al; INTERSTROKE investigators. Risk factors for ischaemic and intracerebral haemorrhagic stroke in 22 countries (the INTERSTROKE study): a case-control study. Lancet. 2010;376:112-123. doi: 10.1016/S0140-6736(10)60834-3.

Kidd, Stewart, Baldry, Johnson, Rossiter, Petrucevitch, Thompson. (1995). The Functional Independence Measure:A Comparative Validity and Reliability Study. Disablility and Rehabilitation, Vol 17, No.1, 10-14.

Kluding P, Gajewski B. (2009). Lowerextremity strength differences predict activity limitations in people with chronic stroke. Phys Ther;89:73-81.

Kristiyawati Sp, dkk (2009). Faktor resiko yang berhubungan dengan kejadian stroke di Rumah Sakit Panti Wilasa Citarum Semarang. Jurnal Ilmu Keperawatan Stikes Telogorejo Semarang.

Kuys SS, Bew PG, Lynch MR, Morrison G, Brauer SG. (2009). Measures of activity limitation on admission to rehabilitation after stroke predict walking speed at discharge: An observational study. Aust J Physiother;55:265-268.

Liu-Ambrose, T., \& Eng, J. J. (2015). Exercise training and recreational activities to promote executive functions in chronic stroke: A proof-of-concept study. Journal of Stroke and Cerebrovascular Diseases, 24(1), 130-137. https://doi.org/10.1016/j.jstrokecerebrovas dis.2014.08.012 
Loewen, SC \& Anderson, BA. 1990. Predictors of Stroke Outcome Using Objective Measurement Scales. Stroke. 21 (1): 78-81.

Makizako, Kabe, Takano, Isobe. (2015). Use of the Berg Balance Scale to Predict Independent Gait After Stroke : A Study of an Inpatient Population in Japan. American Academy of Physical Medicine \& Rehabilitation. Tersedia di http//dx.doi.org/10.1016/j.pmrj.2015.01,00 9.

Maryam, Raden Siti. (2009). Pengaruh Latihan Keseimbangan Fisik terhadap Keseimbangan Tubuh Lansia Di Panti Sosial Tresna Werdha Wilayah Pemda DKI Jakarta. Tesis. Jakarta : FIK UI.

Mozaffarian D, et al. (2015). Circulation. 131:e29-e322.

Park, Seong-Hi dan Lee, Young-Shin. (2016). The Diagnostic Accuracy of The Berg Balance Scale in Predicting Falls. Western Journal of Nursing Research. Doi: 10.1177/0193945916670894.

Wjn.sagepub.com.

Smith, Patricia S; Hembree, Judith A; Thompson, Mary E. 2004. Berg Balance Scale and Functional Reach : determining the best clinical tool for individuals post acute stroke. Doi 10.1191/0269215504cr817oa.

Stevensen, Ted J. (2001). Detecting Change in Patients with Stroke Using the Berg Balance Scale. Australian Journal of Physiotheraphy volume 47.
Thomson, DJ, 2010. Stroke dan Pencegahannya. Jakarta : Arcan.

Tsang YL dan Mak MK. (2004). Sit and reach test can predict mobility of patients recovering from acute stroke. Arch Phys Med Rehabilitation. 85:94-98.

Tyson SF dan Connell, LA. (2009) How to Measure Balance in Clinical Practice. A Systematic Review of The Psychometrics and Clinical Utility of Measure of Balance Activity for Neurological Conditions. Clinical Rehabilitation. Sep; 23 (9): 82440.

Tyson SF dan DeSouza LH. 2004. Reliability and Validity of Functional Balance Tests Post Stroke. Clinical Rehabilitation. 18 (8) : 916-23. 